\title{
Effects of a Strengths Intervention on General and Work-Related Well-Being: The Mediating Role of Positive Affect
}

\author{
Maria Christina Meyers ${ }^{1} \cdot$ Marianne van Woerkom $^{1}$
}

Published online: 30 April 2016

(C) The Author(s) 2016. This article is published with open access at Springerlink.com

\begin{abstract}
In this article, we explore the use of strengths interventions, defined as activities and processes that target the identification, development, and use of individual strengths, as an organizational tool to increase employee well-being. Engaging with one's strengths is assumed to be a pleasant activity that elicits positive emotions like joy, pride, and gratitude, which, in turn, contribute to feelings of overall well-being and satisfaction. Building on this assumption, we hypothesized that participating in a strengths intervention leads to increases in general (i.e., psychological capital and satisfaction with life), and work-related well-being (i.e., increased work engagement and decreased burnout), and that positive affect mediates these effects. To test these hypotheses, we conducted a field experiment with a sample of $N=116$ Dutch working people who were assigned to either an experimental group (participating in a strengths intervention) or a waitlist control group. All participants filled in a pre-intervention, postintervention, and 1 month follow-up questionnaire. Results indicate that participating in a strengths intervention creates short-term increases in employee positive affect and short- and long-term increases in psychological capital. We did not find evidence for a positive, direct effect of the strengths intervention on satisfaction with life, work engagement, and burnout respectively, but we did find support for indirect effects via the mediator positive affect.
\end{abstract}

Keywords Employees · Field experiment $\cdot$ Positive psychology $\cdot$ Strengths $\cdot$ Well-being

\section{Introduction}

Organizations take great interest in promoting employee health and well-being (Danna and Griffin 1999) because happy workers are assumed to be more productive workers (Zelenski et al. 2008; Lyubomirsky et al. 2005) who are better able to cope with the high demands of

Maria Christina Meyers

m.c.meyers@uvt.nl

1 Department of Human Resource Studies, Tilburg University, PO Box 90153, 5000 LE Tilburg, The Netherlands 
the modern world of work (Paauwe 2009). A promising strategy to promote the well-being of employees is the development and use of individual strengths at work (Quinlan et al. 2012; Peterson et al. 2010), because using strengths is, by definition, linked to positive feelings such as excitement and joy. As only few employees report to use their strengths habitually when being at work (Buckingham 2007), enabling strengths use might be a so far overlooked lever to boost employee well-being. To make use of this lever, organizations can implement so-called strengths interventions, defined as training processes aiming at the identification, development, and use of the participants' strengths (Quinlan et al. 2012). Strengths interventions are of particular interest to organizations because they have been found to consistently enhance general well-being (for a review, see: Quinlan et al. 2012), and because they are brief and relatively easy to implement.

To date, there are still considerable gaps in the empirical research on strengths interventions for employees which need to be bridged before a broad implementation of these interventions in the work context can be promoted in good conscience. Most of the existing studies on strengths interventions used samples of children, adolescents, or students instead of adults (Quinlan et al. 2012), and target the use of strengths in daily life, but not particularly in the work context (Meyers et al. 2013). Moreover, the existing studies have mainly focused on indicators of general but not work-related well-being as outcome variables, and have not yet explored the mechanisms through which strengths interventions influence well-being, leaving us with limited knowledge of how or why they work (Quinlan et al. 2012).

Addressing these research gaps, we conducted a field experiment among Dutch employees to investigate the effects of a strengths intervention on employee positive affect, psychological capital (PsyCap), and life satisfaction as indicators of general well-being, as well as on work engagement and burnout as indicators of work-related well-being (Schaufeli 2014). Building on the positive-activity model and the assumption that engaging in positive activities, such as employing one's strengths, makes people feel good about themselves in the short term, which contributes to their longer term well-being (Lyubomirsky and Layous 2013), we furthermore explored the potential mediating role of positive affect in this regard.

\subsection{Individual Strengths and Strengths Interventions}

Individual strengths have been defined as "ways of behaving, thinking or feeling that an individual has a natural capacity for, enjoys doing, and which allow the individual to achieve optimal functioning while they pursue valued outcomes" (Quinlan et al. 2012). Using individual strengths is not only beneficial in that it drives high performance, but also because it is intrinsically motivating, enjoyable, engaging, satisfying, and energizing (Peterson and Park 2006; Linley and Harrington 2006; Peterson and Seligman 2004). Despite these supposed benefits, today's organizations often overlook the potential of organizing work around employee strengths (Peterson and Park 2006). Most employees and leaders cannot readily identify their own strong points (Kaplan and Kaiser 2010; Buckingham and Clifton 2001), and report to not use their strengths very often when being at work (Buckingham 2007). To raise awareness for the value of individual strengths and to stimulate strengths use, organizations can make use of so-called strengths interventions which have been defined as follows:

A strengths intervention is a process designed to identify and develop strengths in an individual or group. Interventions encourage the individual to develop and use their 
strengths, whatever they may be. Their goal is to promote well-being or other desirable outcomes (e.g. academic efficacy) through this process. (Quinlan et al. 2012)

The above definition addresses three elements of strengths interventions: identification, development, and use of strengths. The first of these elements, strengths identification, is about uncovering an individual's most dominant strengths by means of strengths questionnaires (e.g., Peterson and Seligman 2004), feedback from third people (cf. the reflected best self portrait; Roberts et al. 2005), individual reflections, or more open-ended approaches (Quinlan et al. 2012), typically resulting in a list of three to seven strengths (Peterson and Seligman 2004). The second element, strengths development, aims at motivating people to cultivate and refine their strengths. This can, for instance, be achieved by teaching participants to use their strengths wisely, depending on situational factors (Biswas-Diener et al. 2011). The third element of strengths interventions, strengths use, is meant to encourage individuals to use their most prominent strengths more often or in new ways (Seligman et al. 2005). Typically, participants of a strengths intervention are asked to make concrete action plans in which they specify how, how often, when, and in which situations they plan to use their strengths.

Prior research has shown that strengths interventions are an effective tool to increase the overall well-being of children, adolescents, and university students (for a review, see: Quinlan et al. 2012), but only little is known about the effects of strengths interventions on adults and, in particular, working people (Meyers et al. 2013). In line with seminal wellbeing researchers, we conceptualize well-being as a multi-dimensional construct covering context-free or general (e.g., life satisfaction) and context- or domain-specific forms of well-being (e.g., work-related strain; Warr 1999; Diener et al. 1999), and consider both in this paper.

\subsection{The Relationship Between Strengths Interventions and the General Well- Being of Employees}

In this paper, positive affect, positive psychological capital (PsyCap), and satisfaction with life (SWL) will be included as three facets of general well-being that display varying degrees of stability. Positive affect has been defined as "the extent to which a person feels enthusiastic, active, and alert. High positive affect is a state of high energy, full concentration, and pleasurable engagement, whereas low positive affect is characterized by sadness and lethargy" (Watson et al. 1988). As a state, positive affect fluctuates largely across time and situations. State-like variables such as PsyCap, by contrast, fluctuate to a lesser extent than pure states (Luthans et al. 2007). PsyCap is a higher-order construct consisting of the sub-components self-efficacy, hope, optimism, and resilience, and is based on "one's positive appraisal of the particular situation, the physical and social resources available, and the probability of succeeding based on personal effort, upward striving, and perseverance" (Luthans and Youssef 2007). Satisfaction with life is even more stable than PsyCap and displays only minor fluctuations (Fujita and Diener 2005). It has been defined as a personal judgment or appraisal of one's overall life circumstances as compared to standards that individuals set for themselves (Diener et al. 1985).

Results of prior research have supported an association between identifying and working on one's strengths and positive affect (van Woerkom and Meyers 2015; Wood et al. 2011), self-efficacy as a component of PsyCap (Zwart et al. 2015), and satisfaction with life (Douglass and Duffy 2015). Theoretically, a positive association between strengths 
interventions and positive affect can be expected because individuals enjoy applying their strengths (Quinlan et al. 2012), and will feel good about themselves, fulfilled, energized, excited, and invigorated whenever they get the chance to work on or with their strong points (Peterson and Seligman 2004). Moreover, a strengths intervention should lead to increases in PsyCap because working on strengths (1) raises an individual's awareness of personal resources (qualities and assets) that they can use to overcome hardships and setbacks in life (increasing resilience; Park 2004); (2) leads to successful task performance and mastery experiences (Peterson and Seligman 2004; Linley and Harrington 2006) triggering selfefficacy (Bandura 1977); (3) creates positive expectations for the future (building optimism; Luthans et al. 2010); and (4) stimulates individuals to set and pursue self-concordant goals (increasing hope; Luthans et al. 2010). In addition, redirecting an individual's attention towards the positive features they possess by means of a strengths intervention might positively influence their judgment of overall life circumstances, and, hence, their satisfaction with life (Diener et al. 1985). Drawing on humanistic psychology (e.g., Rogers 1961), we furthermore reason that being authentic and having the opportunity to act genuinely and in a way that is congruent to one's self-concept is a hallmark of optimal individual functioning and satisfaction (Sheldon et al. 1997). As individuals who play to their strengths act in accordance with their true selves and experience feelings of authenticity (Peterson and Seligman 2004), strengths interventions should contribute to life satisfaction.

Based on these theoretical arguments and the available research evidence, we hypothesize the following:

Hypothesis 1 Participating in a strengths intervention leads to increases in general wellbeing of employees, that is, increases in positive affect, psychological capital, and satisfaction with life.

\subsection{The Relationship Between Strengths Interventions and Work-Related Well-Being}

Work engagement and burnout represent two related, yet conceptually distinct aspects of work-related well-being (Schaufeli 2014) that can be influenced through targeted workplace interventions (Schaufeli and Salanova 2010; Le Blanc and Schaufeli 2008). Work engagement, on the one hand, has been defined "as a positive, fulfilling, work-related state of mind that is characterized by vigor, dedication, and absorption" (Schaufeli et al. 2002). Employees with high levels of work engagement put much effort and energy in their work, take pride and find inspiration in the work activities they pursue, and immerse themselves fully in their tasks (Schaufeli et al. 2002). Burnout, on the other hand, is a "prolonged response to chronic emotional and interpersonal stressors on the job, and is defined by the three dimensions of exhaustion, cynicism, and inefficacy" (Maslach et al. 2001). That is, burned-out individuals experience feelings of extreme fatigue (exhaustion), develop an indifferent attitude towards their work (cynicism or depersonalization), and show reduced occupational accomplishments (inefficacy; Maslach et al. 2001).

Strengths interventions have been proposed as a suitable tool to influence both engagement and burnout (Schaufeli and Salanova 2010; Chan 2010), because employing strengths is an energizing process (Peterson and Seligman 2004) that renews vigor and counteracts exhaustion (Schaufeli et al. 2002). As developing and using strengths is intrinsically motivating (Peterson and Seligman 2004), strengths interventions can also attenuate the motivation-related symptoms of burnout such as cynical behavior and withdrawal from work (Schaufeli and Taris 2005). Moreover, using strengths makes people feel true to themselves 
and their values (Peterson and Seligman 2004), which conveys a sense of leading a meaningful and significant live, eventually fostering engagement in activities (Schaufeli and Salanova 2010). Finally, it has been proposed that actively putting one's strengths to work can trigger flow experiences (Seligman 2002; Csikszentmihalyi 1990), which are closely related to the absorption component of engagement (Schaufeli et al. 2002), and that strengths can be seen as personal resources that help individuals to cope with stressful situations, making them less prone to experience strain (Bakker and Demerouti 2007).

To date, there is only little empirical research on the relationship between using individual strengths and work-related well-being, with the exception of a study by Harzer and Ruch (2013) in which a positive association between the applicability of one's strengths at work and engagement has been found. However, building on theoretical arguments, we still expect the following:

Hypotheses 2 Participating in a strengths intervention leads to increases in work-related well-being of employees, that is, increases in engagement and decreases in burnout.

\subsection{The Mediating Role of Positive Affect in the Relationship Between Strengths Interventions and Well-Being}

The positive-activity model (Lyubomirsky and Layous 2013) suggests that undertaking positive activities such as working on one's strengths triggers the experience of a range of positively toned emotions such as joy, pride, and gratitude (Lyubomirsky and Layous 2013), which, if they accumulate, contribute to an individual's well-being in the longer term. The effect of positive emotions on well-being can, on the one hand, be explained by the broaden-and-build theory of positive emotions (Fredrickson 2001), proposing that experiencing positive affective states makes people more likely to perceive, appreciate, and embrace the good things that overcome them due to broadening their mindsets. As a consequence, individuals will rate their life as more satisfactory, will build up psychological resources including PsyCap (Fredrickson et al. 2008), and will approach their work tasks with revived interest and dedication. On the other hand, the so-called undoing effect of positive emotions (Fredrickson et al. 2000) implies that positive affective states tend to down-regulate the effects of negative emotions, meaning that positive emotions can serve as a resource that helps individuals to cope with stressful events or threats (Fredrickson et al. 2000), which might otherwise induce burnout (Maslach et al. 2001).

To our knowledge, there are no published studies that investigate positive affect as a mechanism through which strengths interventions increase well-being, although the existence of a similar mechanism has been supported for a positive intervention based on guided meditation (Fredrickson et al. 2008). Therefore, we hypothesize the following:

Hypothesis 3 Positive affect mediates the relationship between strengths interventions and respectively satisfaction with life, PsyCap, engagement, and burnout.

\section{Method}

\subsection{Design and Procedure}

To test our research hypotheses, we developed a strengths intervention in collaboration with a Dutch consultancy specialized in training and development, and conducted a field 
experiment to test the effects of this intervention. A convenience sample of working adults was recruited via the website of the consultancy where the intervention was advertised as a strengths training. We opted to recruit self-selected participants because prior research has shown that self-selection-which is related to positive expectations and motivationincreases the effectiveness of positive interventions (Sin and Lyubomirsky 2009). Depending on their availability, participants could self-subscribe into one of four training groups not knowing that two of these groups would form the experimental group (subsequently, we use this term interchangeably with the term strengths intervention group), while the two others would form the waitlist-control group. Following this procedure, systematic differences between experimental- and control group were avoided (cf. analysis of baseline differences in study variables). While random assignment to conditions would have been preferred, it can lead to very high drop-out rates among working people who are less available than, for instance, students. All participants filled in three questionnaires at three different time-points: a pre-intervention questionnaire (t0), approximately 2 weeks before the intervention, an immediate post-intervention (t1), and 1-month follow-up questionnaire ( $\mathrm{t} 2$ ). At $\mathrm{t} 0$ and $\mathrm{t} 2$, the exact same questionnaires including all study variables were distributed. The post-intervention ( $\mathrm{t} 1$ ) questionnaire only measured positive affect and psychological capital because these variables are conceptualized as a state or state-like variable, meaning that they can potentially fluctuate over short time spans (Watson et al. 1988; Luthans et al. 2007). We did not expect immediate changes in satisfaction with life, engagement, and burnout after the training because these variables are conceptualized as more stable than positive affect and PsyCap (e.g., Schaufeli et al. 2002).

\subsection{The Strengths Intervention}

The half-day strengths intervention we tested reflects the three elements of strengths interventions we described in the theoretical framework: strengths identification, development, and use. Before the training, participants were asked to complete a preparatory assignment with the aim of discovering their three most dominant strengths (strengths identification). To this end, they received a stack of strengths cards with 24 strengths applicable in the working context and some blank cards that could be filled in individually. With the help of these cards and several guiding questions that could be answered individually or by third persons, participants were triggered to search for their own talents. Subsequently, participants took part in a half-day face-to-face training which was given to 40-45 individuals at a time and was facilitated by two professional trainers. The main goal of the training was to stimulate participants to develop and use their strengths in the work context. In addition, we aimed at increasing their understanding of personal, social, and job resources they could draw upon in the process of strengths use and development. As a homework assignment, we asked participants to each choose a partner who would check one's progress with regard to using and developing individual strengths.

\subsection{Measures}

\subsubsection{Positive Affect}

We measured positive affect (PA) with the 10-item PA subscale of the Positive and Negative Affect Schedule (PANAS; Watson et al. 1988). Respondents were asked to indicate the extent to which they were experiencing 10 particular positive affective states at that moment. Examples of these affective states are "interested", "excited", and "strong". 
The five-point Likert response scale ranged from one $(1=$ very slightly or not at all $)$ to five $(5=$ extremely). Cronbach's Alpha values were .85 (t0), .86 (t1), and .90 (t2) respectively.

\subsubsection{Psychological Capital}

Psychological capital was measured with a 16-item measure encompassing four items of the New General Self-efficacy Scale (Chen et al. 2001), four items of the revised Life Orientation Test (LOT-R measuring optimism; Scheier et al. 1994) translated into Dutch by ten Klooster et al. (2010), four items of the State Hope Scale (Snyder et al. 1996), and four items of the Brief Resilience Scale (Smith et al. 2008). Scales for self-efficacy, hope, and resilience were translated to Dutch by means of the translation-back translation procedure. Sample items are 'When facing difficult tasks, I am certain that I can accomplish them' (self-efficacy); 'I'm optimistic about my future' (optimism); 'At the present time, I am energetically pursuing my goals' (hope); and 'I tend to bounce back quickly after hard times' (resilience). As we aimed to capture the state-like nature of the four constructs, we asked respondents to indicate the extent to which they would agree with each of the items at the present moment. If necessary, scales were adapted by reformulating phrases in such a way that generalized statements ('usually', 'always', 'rarely', 'hardly ever') were omitted. All scales were scored on a 5-point Likert scale from one $(1=$ strongly disagree $)$ to five $(5=$ strongly agree). Exploratory factor analysis indicated that the 16 items measured one factor, while parallel analysis showed a two-factor solution. Because the two factor solution was not interpretable in terms of the four pre-existing scales, we decided to continue with a one-factor scale measuring overall PsyCap. Cronbach's alpha values of the combined PsyCap scale were adequate for all three measurement points $(\alpha$ t0 $=.85 ; \alpha$ $\mathrm{t} 1=.86 ; \alpha \mathrm{t} 2=.90)$.

\subsubsection{Satisfaction with Life}

Satisfaction with life was measured with the five-item Satisfaction with Life Scale (SWLS) developed by Diener, Emmons, Larsen, and Griffin (1985). Respondents were asked to indicate their agreement with items such as "In most ways my life is close to my ideal" on a seven-point Likert scale from one ( $1=$ strongly disagree) to seven $(7=$ strongly agree). Cronbach's alpha values were adequate with .88 (t0) and $.92(\mathrm{t} 2)$ respectively.

\subsubsection{Work Engagement}

Work engagement was measured with the nine-item version of the Utrecht Work Engagement Scale (UWES-9; Schaufeli et al. 2006). A sample item is "At my work, I feel bursting with energy". Answers could be given on a seven-point Likert scale from one $(1=$ never $)$ to seven $(7=$ always/every day). Cronbach's Alpha values were .95 (t0) and $.95(\mathrm{t} 2)$, respectively.

\subsubsection{Burnout}

We measured burnout with the five-item exhaustion subscale of the Utrechtse Burnout Scale (UBOS-A; Schaufeli and van Dierendonck 2000). Answers could be given on a 
7 -point scale from one $(1=$ never $)$ to seven $(7=$ always/every day $)$. A sample item is "I feel burned out from my work". Cronbach's Alpha were .94 (t0). and .92 (t2) for the two measurement points.

\subsection{Sample}

At pre-measurement, $N=179$ people completed the research questionnaire. $71.5 \%$ of them were female, and their mean age was 42.39 years. The majority of the sample was highly educated: $45.8 \%$ completed vocational higher education, and $36.3 \%$ completed academic education. They were working in diverse sectors, with business services $(15.6 \%)$, government $(14 \%)$, and healthcare $(12.8 \%)$ as the three biggest represented sectors. The average tenure of the participants was 8.79 years, and $25.7 \%$ held a leadership function. With the exception of gender and a slight tendency towards higher education, these demographic characteristics are fairly representative of the Dutch working population. 130 participants filled in all three questionnaires $(N=67$ for the experimental group and $N=63$ for the control group). The attrition rate was $27.4 \%$. Attrition analysis revealed no significant differences between the remainders and drop-outs on the demographic variables gender, age, education, sector, tenure, or leadership function. Due to deletion of four univariate outliers, and due to respondents with missing values on some of the study variables, the minimum sample size for all analyses was further reduced to $N=116$ respondents.

\subsection{Data Analysis}

In order to investigate the effects of the strengths intervention on the five indicators of wellbeing, we conducted several mixed between-within subject analyses of variance (ANOVA's) with group as a between-subject factor and time as a within-subject factor. Prior to conducting these analyses, data was checked for univariate normality and for outliers. Analysis of univariate normality revealed that all variables except for burnout were reasonably normally distributed. Burnout was positively skewed which led us to transform it with the square root transformation (Tabachnick and Fidell 2007). Analysis of univariate outliers furthermore indicated that there were four cases with outlying values (more than three standard deviations above or below the mean) on at least one of the study variables, which led us to exclude those cases from further analysis (Tabachnick and Fidell 2007). In addition to the mixed betweenwithin subject ANOVAs to investigate effects on the different well-being variables over time, we conducted sequential multiple regression analyses to investigate the mediating role of positive affect (Tabachnick and Fidell 2007). We tested the significance of the hypothesized indirect effect by constructing $95 \%$ bootstrap confidence intervals based on 5000 bootstrap samples (Hayes and Preacher 2013).

\section{Results}

\subsection{Preliminary Analysis and Descriptives}

We conducted a multivariate analysis of variance (MANOVA) to test whether there were significant differences between the experimental and control group on any of the five study 
variables prior to the strengths intervention (t0). Results of the MANOVA indicated that the groups differed neither on a linear combination of positive affect, PsyCap, satisfaction with life, engagement, and burnout (Wilks' Lambda $=.99, F(5,162)=.09, p=.99$, partial $\eta^{2}=.003$ ), nor on any of the variables when considered separately. Table 1 displays means, standard deviations, and intercorrelations of all study variables.

\subsection{Main Analysis: ANOVA's}

Results of the five mixed between-within subjects ANOVA's revealed the following. First, when analyzing positive affect as a dependent variable, we found a significant main effect of time [Wilks' Lambda $=.95, F(2,124)=3.34, p<.04$, partial $\eta^{2}=.05$ ], and a nonsignificant main effect of group $\left[F(1,125)=1.50, p=.22\right.$, partial $\left.\eta^{2}=.01\right]$. The time $\times$ group interaction effect was significant (Wilks' Lambda $=.91, F(2,124)=5.99$, $p<.01$, partial $\eta^{2}=.09$ ), which indicates that the changes in positive affect over time were different for the two groups. The interaction plot (see Fig. 1a) indicates that the participants of the experimental group experienced a boost in positive affect at postmeasurement (t1), but that this boost was not maintained over the 1-month follow-up period. The control group, in comparison, displayed relatively stable (slightly dropping) levels of positive affect across the three measurement points. In the second ANOVA including PsyCap as a dependent variable, the main effect of time was again significant $\left(\right.$ Wilks' Lambda $=.88, F(2,119)=7.98, p=.001$, partial $\left.\eta^{2}=.12\right)$, whereas the main effect of group was not $\left[F(1,120)=.09, p=.77\right.$, partial $\left.\eta^{2}=.00\right]$. The time $\times$ group interaction effect was found to be significant (Wilks' Lambda $=.95, F(2,119)=3.30$, $p<.05$, partial $\left.\eta^{2}=.05\right)$. The interaction plot shows that the experimental group experienced gains in PsyCap at post-measurement (t1) which were maintained over the 1-month follow-up period (t2), whereas the control group displayed relatively stable PsyCap values across the three measurement points (see Fig. 1b). Paired-sample t-tests confirmed that the increases in PsyCap at both measurement points were significant for the experimental group. Third, the repeated measures ANOVA which we conducted to investigate the intervention's effects of satisfaction with life indicated that the main effect of time (Wilks' Lambda $=.99, F(1,140)=2.01, p=.16$, partial $\left.\eta^{2}=.01\right)$, the main effect of group $\left[F(1,120)=.26, p=.61\right.$, partial $\left.\eta^{2}=.00\right]$, and the time $\times$ group interaction effect [Wilks' Lambda $=.995, F(1,140)=.74, p=.39$, partial $\eta^{2}=.01$ ] were non-significant. The interaction plot shows that the experimental group experiences slight gains in satisfaction with life over the 1-month measurement period, whereas the control group displays relatively stable levels of this variable (see Fig. 1c). However, a paired-sample $t$ test indicated that the increase of the experimental group was not significant. Taken together, these results provide partial support for Hypothesis 1 regarding the positive effect of the strengths intervention on general well-being.

Similar results were found in the fourth ANOVA, investigating the effect of the intervention on work engagement. Neither the main effect of time [Wilks' Lambda $=.999$, $F(1,133)=.16, p=.69$, partial $\left.\eta^{2}=.00\right]$, nor the main effect of group $[F(1,133)=.67$, $p=.61$, partial $\left.\eta^{2}=.00\right]$, nor the time $\times$ group interaction turned out to be significant [Wilks' Lambda $=.99, F(1,133)=.78, p=.38$, partial $\left.\eta^{2}=.01\right]$. The interaction plot revealed that the experimental group displayed stable levels of engagement over time, whereas the control group's engagement slightly decreased (see Fig. 1d). A paired-sample t-test revealed that this change over time was not significant. Finally, results for burnout followed a similar pattern. Neither the main effect of time [Wilks' Lambda $=1.00$, $F(1,136)=.11, p=.74$, partial $\left.\eta^{2}=.00\right]$, nor of group $[F(1,136)=1.45, p=.23$, 


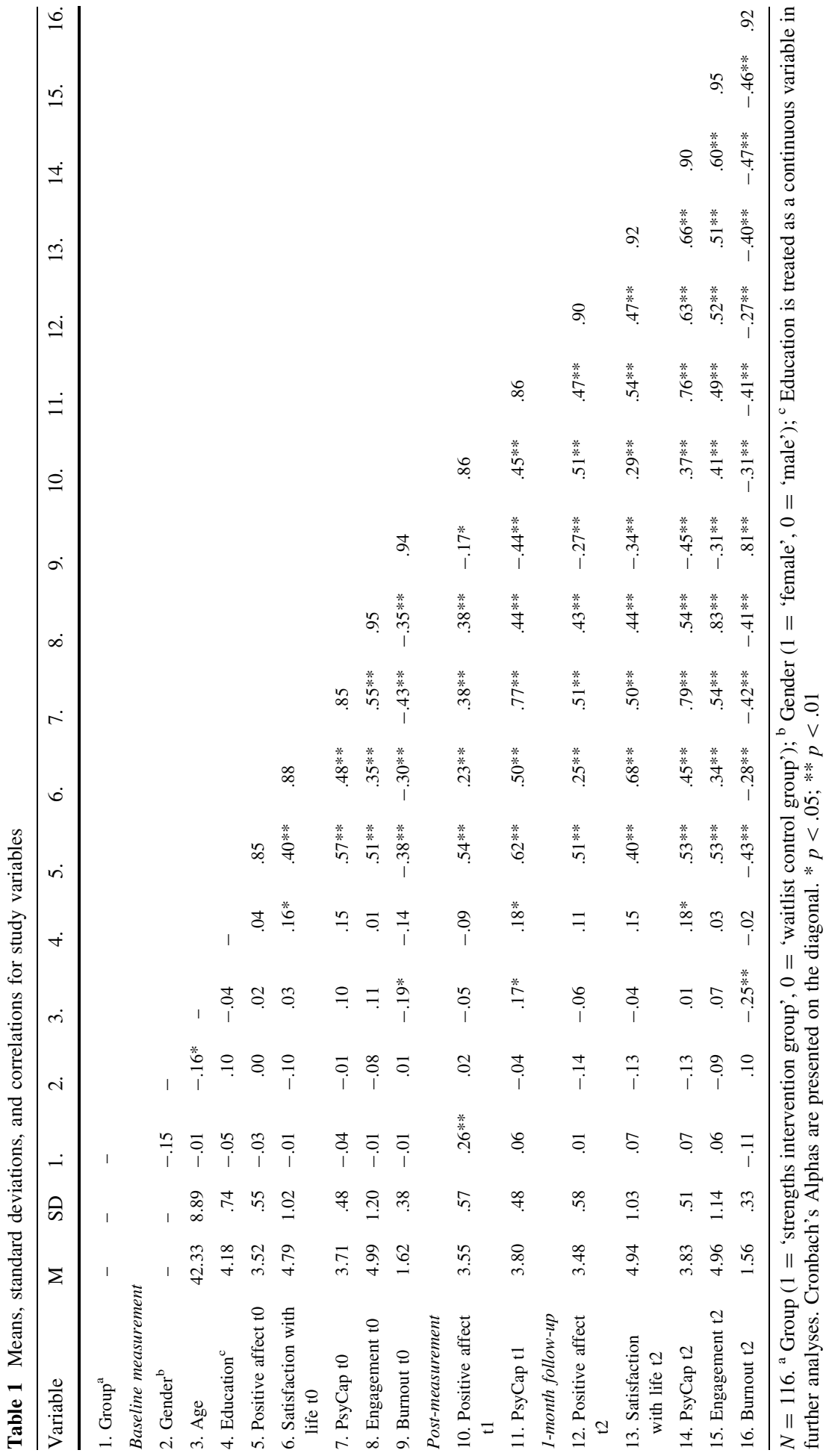



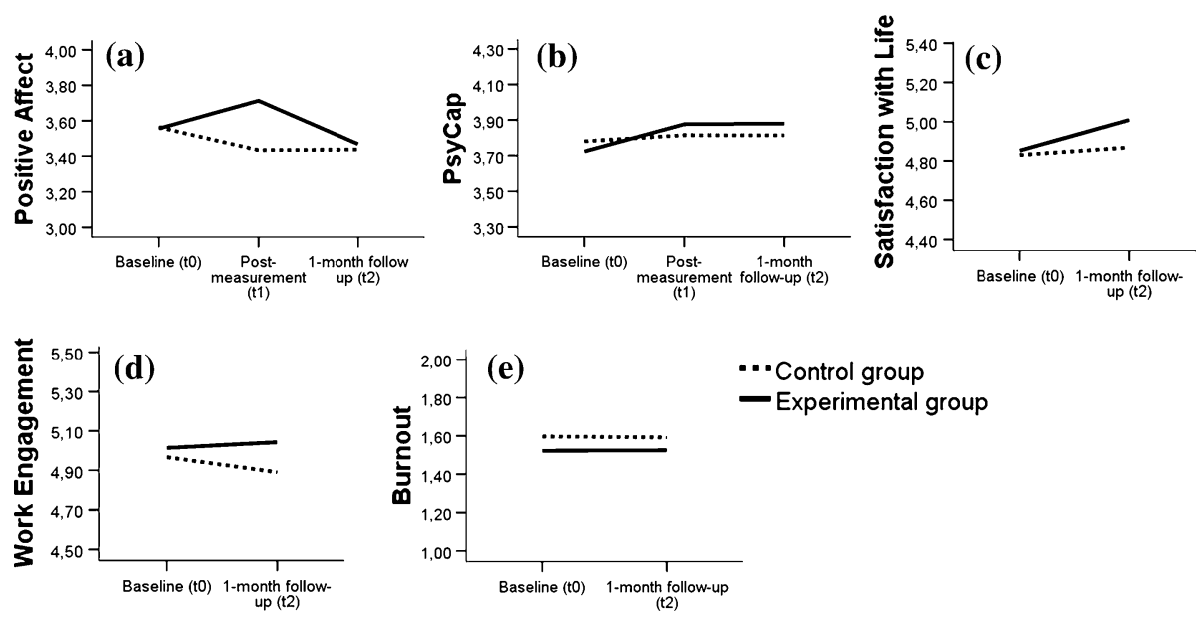

Fig. 1 Interactions plots of the effects of the strengths intervention on mean scores of positive affect (a), PsyCap (b), satisfaction with life (c), work engagement (d), and burnout (e) over time

partial $\left.\eta^{2}=.01\right]$, nor the time $\times$ group interaction effect [Wilks' Lambda $=1.00$, $F(1,136)=.05, p=.82$, partial $\eta^{2}=.00$ ] were significant. Checking the interaction plots clarifies that both groups displayed relatively stable values of burnout over time (see Fig. 1e). Taken together, these results led us to reject Hypothesis 2 regarding the positive direct effect of the strengths intervention on work-related well-being.

\subsection{Main Analysis: Regression Analyses}

Building forth on the results of the repeated measures ANOVA's, we investigated whether the intervention influenced satisfaction with life, PsyCap, work engagement, and burnout indirectly via post-measurement increases in positive affect. To this end, we conducted a multiple regression analysis with positive affect at post-measurement (t1) as a dependent variable in a first step (see Table 2). Results revealed that the strengths intervention significantly predicted post-measurement ( $\mathrm{t} 1)$ scores on positive affect $(\beta=.28, p<.001$, $\left.\Delta R^{2}=.08\right)$, while controlling for gender, age, education, and baseline scores on positive affect $(\mathrm{t} 0)$. In four other regression analysis (see Table 3 ), we regressed satisfaction with life, PsyCap, work engagement, and burnout at the 1-month follow-up (t2) on gender, age, education, the baseline score of the respective dependent variable (t0) (these control variables were entered in the first block), the grouping variable (entered in the second block), and positive affect at post-measurement (t1) (entered in the third block). In these regression analyses we found that the grouping variable did not have a significant positive effect on satisfaction with life, PsyCap, and engagement, but that it had a marginally significant, negative effect on burnout $\left(\beta=-.09, p<.10, \Delta R^{2}=.01\right)$. Furthermore, we found that positive affect at post-measurement (t1) had a significant, positive effect on satisfaction with life $\left(\beta=.15, p<.05, \Delta R^{2}=.02\right)$, a non-significant effect on PsyCap $\left(\beta=.06, p=.29, \Delta R^{2}=.00\right)$, a marginally significant, positive effect on engagement $\left(\beta=.10, p<.10, \Delta R^{2}=.01\right)$, and a significant, negative effect on burnout $(\beta=-.16$, $p<.01, \Delta R^{2}=.02$ ). The latter findings hint at the potential mediating role of positive affect in the relationship between the strengths intervention and respectively satisfaction 
Table 2 Results of hierarchical regression analysis predicting positive affect at the immediate post-measurement (t1)

\begin{tabular}{|c|c|c|c|c|}
\hline & \multicolumn{4}{|c|}{ Positive affect (t1) } \\
\hline & $B(S E)$ & $\beta$ & $B(S E)$ & $\beta$ \\
\hline \multicolumn{5}{|l|}{ Step 1} \\
\hline Gender $^{a}$ & $.03(.09)$ & .02 & $.08(.09)$ & .06 \\
\hline Age & $-.00(.01)$ & -.07 & $-.00(.00)$ & -.06 \\
\hline Education $^{\mathrm{b}}$ & $-.09(.05)$ & -.11 & $-.08(.05)$ & -.10 \\
\hline Positive affect (t0) & $.57(.07)$ & $.55^{* * *}$ & $.58(.07)$ & $.56^{* * *}$ \\
\hline \multicolumn{5}{|l|}{ Step 2} \\
\hline \multirow[t]{2}{*}{ Group $^{c}$} & & & $.32(.08)$ & $.28 * * *$ \\
\hline & $R^{2}=.31$ & & $\Delta R^{2}=.08^{* * *}$ & \\
\hline
\end{tabular}

$\overline{{ }^{\mathrm{a}} \text { Gender }\left(1=\text { 'female', } 0=\text { 'male'); }{ }^{\mathrm{b}} \text { Treated as a continuous variable; }{ }^{\mathrm{c}} \text { Group }(1=\text { 'experimental }\right.}$ group', $0=$ 'control group'); ${ }^{\#} p<.10 ; * p<.05 ; * * p<.01 ; * * p<.001$

with life, work engagement, and burnout. Computation of $95 \%$ bootstrap confidence intervals confirmed that the indirect effects of the strengths intervention via the mediator positive affect were significant for satisfaction with life (95\% CI [.00,.18]), engagement (95\% CI $[.01, .18])$, and burnout $(95 \%$ CI $[-.05,-.00])$, but not for PsyCap (95\% CI $[-.01, .06])$.

\section{Discussion}

The purpose of the present paper was to investigate the effects of a brief strengths intervention, designed to facilitate the identification, development, and use of individual strengths, on several indicators of employees' general and work-related well-being.

In line with the idea that using strengths makes individuals feel good about themselves (Peterson and Seligman 2004), results of the field experiment we conducted pointed out that strengths interventions trigger short-term increases in positive affective states such as excitement, interest, enthusiasm, and pride. These favorable effects have, however, not been sustained until 1 month after the intervention, which might be explained by the fact that affective states can fluctuate from one moment to the next depending on situational factors (Watson et al. 1988). Even though the boost in positive affect itself was not sustainable, results revealed that positive affect (at post-measurement) mediates the relationship between the strengths intervention and three out of four more stable well-being indicators, namely satisfaction with life, work engagement, and burnout (measured at the 1-month follow up). These findings are in line with the positive-activity model (Lyubomirsky and Layous 2013), suggesting that involvement in positive activities such as working on strengths leads to short-term increases in positive affect, which contribute to an individual's longer-term well-being, and with the broaden-and build theory of positive emotions (Fredrickson 2001), which explains the beneficial effects of seemingly minor incidences such as momentary increases in positive affect in more detail. According to this theory, positive emotions broaden an individual's perspective upon their surroundings, which makes them see and appreciate more positive aspects in their lives (influencing life satisfaction), and which induces exploratory behavior and curiosity, eventually triggering employees to approach their work tasks with greater interest and enthusiasm (influencing 


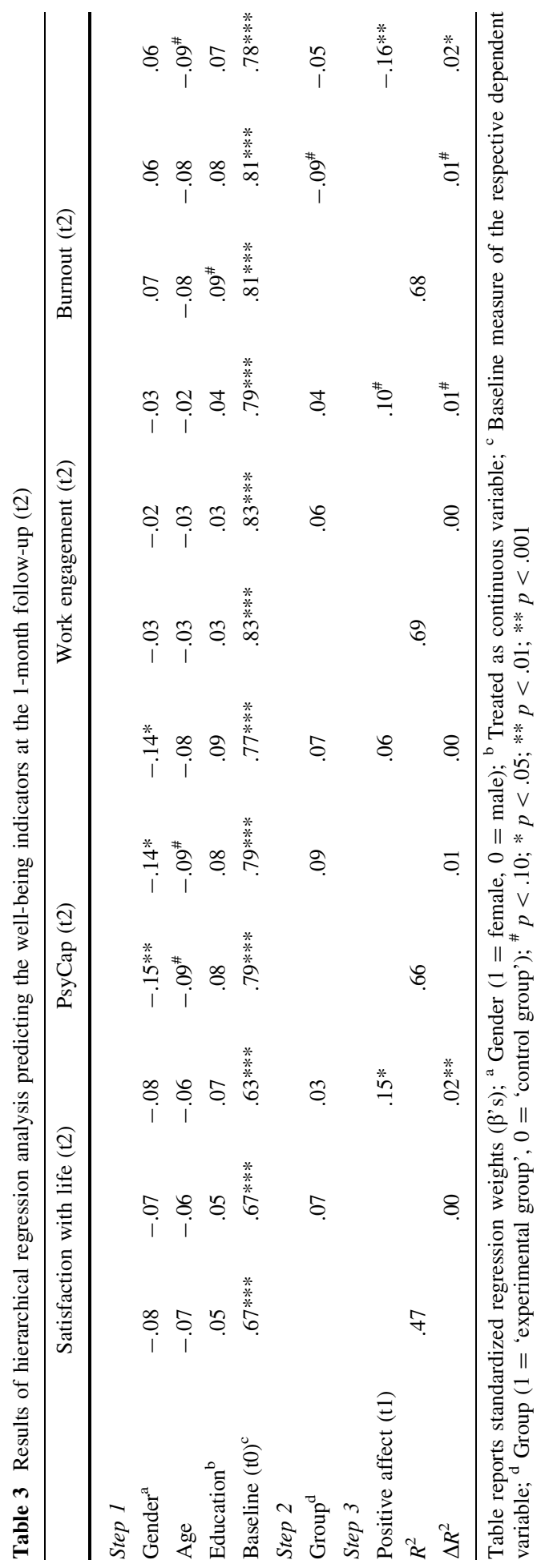


engagement; Fredrickson 2001). Moreover, positive emotions can undo the effects of negative emotions and events, meaning that they can act as a buffer against work-related stressors and, ultimately, burnout (cf. the undoing effect of positive emotions; Fredrickson et al. 2000). Contrary to the expectation that increases in positive affect would also contribute to building personal resources such as PsyCap over time (Fredrickson 2001), the mediating effect of positive affect was not supported in this regard. Instead, only direct effects of the strengths intervention on PsyCap at the immediate post-measurement and the 1-month follow up were found. These positive, direct effects can be explained by the fact that the strengths intervention draws on many known predictors of PsyCap such as mastery experiences, an emphasis on personal assets, positive feedback, and goal-setting (Luthans et al. 2008).

No direct effects of the strengths intervention on the other three well-being indicators were found, except for a marginally significant, negative effect of the intervention on burnout. As more stable indicators of well-being, satisfaction with life, engagement, and burnout might be more difficult to change and might require longer interventions with obligatory follow-up meetings and assignments (cf. literature on transfer of training; Baldwin and Ford 1988) for direct effects to become visible. Life satisfaction, for instance, has been found to be stable over time for a majority of people, and the minority of people who display alternating levels of satisfaction with life have usually undergone considerable changes in life circumstances such as losing their job or spouse (Fujita and Diener 2005). In light of this, a half-day strengths intervention as used in the present study might just not be enough to influence the salient information a person accesses when appraising his or her overall life circumstances (Diener et al. 1985). In line with this assumption, it has been found that satisfaction with life could be enhanced through an extensive, 12-week strengths intervention (Rust et al. 2009), but not through a relatively short, 3-week online intervention (Mitchell et al. 2009). Next to the reasoning that more extensive interventions might be required, not finding direct effects of the strengths intervention on work-related well-being might also be partly explained by the participants' high initial levels of engagement and low levels of burnout which makes it more difficult to achieve and detect changes for the better (ceiling effect; Wang et al. 2008).

\subsection{Theoretical and Practical Implications}

The present study aimed to contribute to the theoretical understanding of strengths interventions and the way they function in the work context. Along general lines, we found support for the propositions derived from the positive-activity model (Lyubomirsky and Layous 2013), namely for the positive effect of strengths interventions on the well-being of working people and the mediating role of positive affect in this regard. However, while we did find direct effects on indicators of general well-being (positive affect and PsyCap), we only found an indirect but not a direct effect of the strengths intervention on the two indicators of work-related well-being (engagement and burnout). Building on research that highlights the importance of actually having the opportunity to apply strengths at work (e.g., Harzer and Ruch 2013), we reason that strengths interventions might only be beneficial for work-related well-being if certain conditions are met. On the one hand, the intervention must succeed in motivating the participants to develop and use their strengths at work. On the other hand, even if the participants are motivated, the work context must allow for the application of their strengths. In the worst case, strengths interventions could actually have detrimental effects on work-related well-being if employees discover that there is a bad fit between their current job and their strengths. Building on this, we suggest 
that the applicability of strengths at work might be a meaningful moderator that alters the relationship between strengths interventions and work-related well-being.

In addition to contributing to theory, this study makes a practical contribution by showing that even a very brief strengths intervention can significantly enhance employee positive affect and psychological capital as indicators of an employee's general well-being in the short term. In addition, these interventions seem to favorably impact an employee's work-related well-being via short-term increases in positive affect. These results hint at the potential utility of strengths interventions as an organizational tool to promote and protect the well-being of employees, which is relevant for many employers (Danna and Griffin 1999). In addition, organizations might consider increases in PsyCap as valuable, because prior research has shown that developing PsyCap leads to higher individual performance (Luthans et al. 2010). Furthermore, we reason that strengths interventions will result in even greater benefits for employers when they are conducted in organizations that are characterized by a strengths-based climate, that is, a climate in which individual strengths are appreciated and in which employees get the chance to develop and use their strengths (van Woerkom and Meyers 2014). Research has shown that such a climate is not only related to higher employee well-being, but also to higher in-role and extra-role performance (van Woerkom and Meyers 2014).

\subsection{Limitations and Directions for Future Research}

The present study is subject to limitations concerning the sample, the research model, and the research design. First, the sample size of $N=116$ is small in comparison to many cross-sectional or longitudinal studies, and a small sample diminishes the statistical power of the analyses. However, the sample size is reasonable given that a field experiment with three measurement points requires a much higher time investment of participants than cross-sectional survey research. In addition, the sample consisted of self-selected participants since prior research has shown that positive psychology interventions work better if individuals choose to participate themselves (Sin and Lyubomirsky 2009). Future research needs to investigate whether positive psychology interventions are effective if participants are not interested in or drawn to such interventions. Relatedly, the possibility for selfselection might also explain why the sample was skewed towards female participants: As women tend to be drawn to other topics than men (e.g., social or interpersonal instead of performance-related topics; Knobloch-Westerwick et al. 2006), the positively toned strengths training might have been more appealing to them. Nonetheless, given that gender did not correlate with any of the dependent variables in this study, and that our findings are in line with other studies on positive interventions that used more gender-homogenous samples (Seligman et al. 2005), we have no reason to assume that our findings are only applicable to female populations.

Second, with regard to the research model, we investigated only one of four possible mediators proposed by the positive-activity model (Lyubomirsky and Layous 2013). While we did investigate the mediating role of positive affect, we did not measure positive thoughts, positive behaviors, or need satisfaction. In this exploratory study, we chose to focus on positive affect only, because available theory and research evidence indicated that it might be the key mechanism through which strengths interventions operate. Building on the results of this study, we do, however, suggest that future research also takes into account the other three potential mediators included in the model. Third, participants in this study were not randomly assigned to the experimental and waitlist-control groups, because working people might drop out of a study if they cannot choose a training date that 
fits their work schedule themselves. As the participants did not know that the training groups they could subscribe for differed in terms of their status in this research project, we can assume that the procedure comes close to a random allocation. Comparisons of the preintervention scores of the experimental and control group on the study variables corroborated this assumption. A final limitation regarding the research design concerns the limited follow-up period. We followed participants over the period of a month in this study, but it would be advisable to expand the period to at least 6 months in future research so that longer-term effects can be captured.

\section{Conclusion}

The present study has shown that strengths interventions are a purposeful tool that can be implemented in work contexts to increase the general and work-related well-being of employees. It appears that positive affect plays an important role in this regard, because employees experienced short-term increases in positive affect in response to the intervention which, in turn, led to increases in engagement, burnout, and satisfaction with life in the longer-term. In addition, the strengths intervention brought about direct, short- and long-term increases in employees' psychological capital, which, as prior research has shown, is linked to beneficial work outcomes such as individual performance. Even though these results are an important first contribution to the knowledge base with regard to strengths interventions as an organizational tool, there is still much to be learned about, among others, the range and sustainability of their effects, their operating mechanisms next to positive affect, and the boundary conditions under which they work best.

Open Access This article is distributed under the terms of the Creative Commons Attribution 4.0 International License (http://creativecommons.org/licenses/by/4.0/), which permits unrestricted use, distribution, and reproduction in any medium, provided you give appropriate credit to the original author(s) and the source, provide a link to the Creative Commons license, and indicate if changes were made.

\section{References}

Bakker, A. B., \& Demerouti, E. (2007). The job demands-resources model: State of the art. Journal of Managerial Psychology, 22(3), 309-328. doi:10.1108/02683940710733115.

Baldwin, T. T., \& Ford, J. K. (1988). Transfer of training: A review and directions for future research. Personnel Psychology, 41, 63-105.

Bandura, A. (1977). Self-efficacy: Toward a unifying theory of behavioral change. Psychological Review, 84(2), 191-215. doi:10.1037/0033-295x.84.2.191.

Biswas-Diener, R., Kashdan, T. B., \& Minhas, G. (2011). A dynamic approach to psychological strength development and intervention. The Journal of Positive Psychology, 6(2), 106-118. doi:10.1080/ 17439760.2010 .545429 .

Buckingham, M. (2007). Go put your strengths to work: 6 powerful steps to achieve outstanding performance. New York, NY: Free Press.

Buckingham, M., \& Clifton, D. O. (2001). Now, discover your strengths. New York: Free Press.

Chan, D. W. (2010). Teacher burnout revisited: Introducing positive intervention approaches based on gratitude and forgiveness. Educational Research Journal, 25(2), 165-186.

Chen, G., Gully, S. M., \& Eden, D. (2001). Validation of a new general self-efficacy scale. Organizational Research Methods, 4(1), 62-83. doi:10.1177/109442810141004.

Csikszentmihalyi, M. (1990). Flow. The psychology of optimal experience. New York: Harper \& Row.

Danna, K., \& Griffin, R. W. (1999). Health and well-being in the workplace: A review and synthesis of the literature. Journal of Management, 25(3), 357-384. doi:10.1177/014920639902500305. 
Diener, E., Emmons, R. A., Larsen, R. J., \& Griffin, S. (1985). The satisfaction with life scale. Journal of Personality Assessment, 49(1), 71-75. doi:10.1207/s15327752jpa4901_13.

Diener, E., Suh, E. M., Lucas, R. E., \& Smith, H. L. (1999). Subjective well-being: Three decades of progress. Psychological Bulletin, 125(2), 276-302. doi:10.1037/0033-2909.125.2.276.

Douglass, R. P., \& Duffy, R. D. (2015). Strengths use and life satisfaction: A moderated mediation approach. Journal of Happiness Studies, 16(3), 619-632.

Fredrickson, B. L. (2001). The role of positive emotions in positive psychology: The broaden-and-build theory of positive emotions. American Psychologist, 56(3), 218-226. doi:10.1037/0003-066X.56.3. 218.

Fredrickson, B. L., Cohn, M. A., Coffey, K. A., Pek, J., \& Finkel, S. M. (2008). Open hearts build lives: Positive emotions, induced through loving-kindness meditation, build consequential personal resources. Journal of Personality and Social Psychology, 95(5), 1045-1062. doi:10.1037/a0013262.

Fredrickson, B. L., Mancuso, R., Branigan, C., \& Tugade, M. (2000). The undoing effect of positive emotions. Motivation and Emotion, 24(4), 237-258. doi:10.1023/a:1010796329158.

Fujita, F., \& Diener, E. (2005). Life satisfaction set point: Stability and change. Journal of Personality and Social Psychology, 88(1), 158-164.

Harzer, C., \& Ruch, W. (2013). The application of signature character strengths and positive experiences at work. Journal of Happiness Studies, 14(3), 965-983. doi:10.1007/s10902-012-9364-0.

Hayes, A. F., \& Preacher, K. J. (2013). Statistical mediation analysis with a multicategorical independent variable. British Journal of Mathematical and Statistical Psychology,. doi:10.1111/bmsp.12028.

Kaplan, R. E., \& Kaiser, R. B. (2010). Toward a positive psychology for leaders. In P. A. Linley, S. Harrington, \& N. Garcea (Eds.), Oxford handbook of positive psychology and work (pp. 107-117, Oxford library of psychology). New York: Oxford University Press.

Knobloch-Westerwick, S., Brück, J., \& Hastall, M. R. (2006). The gender news use divide: Impacts of sex, gender, self-esteem, achievement, and affiliation motive on German newsreaders' exposure to news topics. Communications, 31(3), 329-345.

Le Blanc, P. M., \& Schaufeli, W. B. (2008). Burnout interventions: An overview and illustration. In J. R. B. Halbesleben (Ed.), Handbook of stress and burnout in health care (pp. 201-216). New York: Nova Science Publishers.

Linley, P. A., \& Harrington, S. (2006). Playing to your strengths. The Psychologist, 19(2), 86-89.

Luthans, F., Avey, J. B., Avolio, B. J., \& Peterson, S. J. (2010). The development and resulting performance impact of positive psychological capital. Human Resource Development Quarterly, 21(1), 41-67. doi:10.1002/hrdq.20034.

Luthans, F., Avey, J. B., \& Patera, J. L. (2008). Experimental analysis of a web-based training intervention to develop positive psychological capital. Academy of Management Learning \& Education, 7(2), 209-221.

Luthans, F., \& Youssef, C. M. (2007). Emerging positive organizational behavior. Journal of Management, 33(3), 321-349. doi:10.1177/0149206307300814.

Luthans, F., Youssef, C. M., \& Avolio, B. J. (2007). Psychological capital. Oxford: Oxford University Press.

Lyubomirsky, S., King, L., \& Diener, E. (2005). The benefits of frequent positive affect: Does happiness lead to success? Psychological Bulletin, 131, 803-855.

Lyubomirsky, S., \& Layous, K. (2013). How do simple positive activities increase well-being? Current Directions in Psychological Science, 22(1), 57-62. doi:10.1177/0963721412469809.

Maslach, C., Schaufeli, W. B., \& Leiter, M. P. (2001). Job burnout. Annual Review of Psychology, 52(1), 397-422. doi:10.1146/annurev.psych.52.1.397.

Meyers, M. C., Van Woerkom, M., \& Bakker, A. B. (2013). The added value of the positive: A literature review of positive psychology interventions in organizations. European Journal of Work and Organizational Psychology, 22(5), 618-632. doi:10.1080/1359432X.2012.694689.

Mitchell, J., Stanimirovic, R., Klein, B., \& Vella-Brodrick, D. (2009). A randomised controlled trial of a self-guided internet intervention promoting well-being. Computers in Human Behavior, 25(3), 749-760. doi:10.1016/j.chb.2009.02.003.

Paauwe, J. (2009). HRM and performance: Achievements, methodological issues and prospects. Journal of Management Studies, 46, 129-142. doi:10.1111/j.1467-6486.2008.00809.x.

Park, N. (2004). Character strengths and positive youth development. The ANNALS of the American Academy of Political and Social Science, 591(1), 40-54. doi:10.1177/0002716203260079.

Peterson, C., \& Park, N. (2006). Character strengths in organizations. Journal of Organizational Behavior, 27(8), 1149-1154. doi:10.1002/job.398.

Peterson, C., \& Seligman, M. E. P. (2004). Character strengths and virtues: A handbook and classification. New York: Oxford University Press. 
Peterson, C., Stephens, J. P., Park, N., Lee, F., \& Seligman, M. E. P. (2010). Strengths of character and work. In P. A. Linley, S. Harrington, N. Garcea, P. A. Linley, S. Harrington, \& N. Garcea (Eds.), Oxford handbook of positive psychology and work. (pp. 221-231, Oxford library of psychology). New York, NY: Oxford University Press.

Quinlan, D., Swain, N., \& Vella-Brodrick, D. A. (2012). Character strengths interventions: Building on what we know for improved outcomes. Journal of Happiness Studies, 13(6), 1145-1163. doi:10.1007/ s10902-011-9311-5.

Roberts, L. M., Dutton, J. E., Spreitzer, G. M., Heaphy, E. D., \& Quinn, R. E. (2005). Composing the reflected best-self portrait: Building pathways for becoming extraordinary in work organizations. The Academy of Management Review, 30(4), 712-736.

Rogers, C. R. (1961). On becoming a person. New York: Houghton Mifflin.

Rust, T., Diessner, R., \& Reade, L. (2009). Strengths only or strengths and relative weaknesses? A preliminary study. Journal of Psychology: Interdisciplinary and Applied, 143(5), 465-476. doi:10.3200/ jrl.143.5.465-476.

Schaufeli, W. B. (2014). What is engagement? In C. Truss, R. Delbridge, K. Alfes, A. Shantz, \& E. Soane (Eds.), Employee engagement in theory and practice (pp. 15-35). Abingdon: Routledge.

Schaufeli, W. B., Bakker, A. B., \& Salanova, M. (2006). The measurement of work engagement with a short questionnaire. Educational and Psychological Measurement, 66(4), 701-716. doi:10.1177/ 0013164405282471.

Schaufeli, W. B., \& Salanova, M. (2010). How to improve work engagement? In S. Albrecht (Ed.), The handbook of employee engagement: Perspectives, issues, research and practice (pp. 399-415). Northampton, MA: Edwin Elgar.

Schaufeli, W. B., Salanova, M., González-Romá, V., \& Bakker, A. B. (2002). The measurement of engagement and burnout: A two sample confirmatory factor analytic approach. Journal of Happiness Studies, 3(1), 71-92. doi:10.1023/a:1015630930326.

Schaufeli, W. B., \& Taris, T. W. (2005). The conceptualization and measurement of burnout: Common ground and worlds apart. Work \& Stress, 19(3), 256-262. doi:10.1080/02678370500385913.

Schaufeli, W. B., \& van Dierendonck, D. (2000). Utrechtse Burnout Schaal (UBOS): Testhandleiding [Utrecht Burnout Scale. Test Manual]. Amsterdam: Harcourt Test Services.

Scheier, M. F., Carver, C. S., \& Bridges, M. W. (1994). Distinguishing optimism from neuroticism (and trait anxiety, self-mastery, and self-esteem): A reevaluation of the Life Orientation Test. Journal of Personality and Social Psychology, 67(6), 1063-1078. doi:10.1037/0022-3514.67.6.1063.

Seligman, M. E. P. (2002). Authentic happiness: Using the new positive psychology to realize your potential for lasting fulfilment. New York: Free Press.

Seligman, M. E. P., Steen, T. A., Park, N., \& Peterson, C. (2005). Positive psychology progress: Empirical validation of interventions. American Psychologist, 60(5), 410-421.

Sheldon, K. M., Ryan, R. M., Rawsthorne, L. J., \& Ilardi, B. (1997). Trait self and true self: Cross-role variation in the Big-Five personality traits and its relations with psychological authenticity and subjective well-being. Journal of Personality and Social Psychology, 73(6), 1380-1393.

Sin, N. L., \& Lyubomirsky, S. (2009). Enhancing well-being and alleviating depressive symptoms with positive psychology interventions: a practice-friendly meta-analysis. Journal of Clinical Psychology, 65(5), 467-487. doi:10.1002/jclp.20593.

Smith, B. W., Dalen, J., Wiggins, K., Tooley, E., Christopher, P., \& Bernard, J. (2008). The Brief Resilience Scale: Assessing the ability to bounce back. International Journal of Behavioral Medicine, 15(3), 194-200. doi:10.1080/10705500802222972.

Snyder, C. R., Sympson, S. C., Ybasco, F. C., Borders, T. E., Babyak, M. A., \& Higgins, R. L. (1996). Development and validation of the State Hope Scale. Journal of Personality and Social Psychology, 2, 321-335.

Tabachnick, B. G., \& Fidell, L. S. (2007). Using multivariate statistics (5th ed.) (Using multivariate statistics (5th ed.).). Boston, MA: Allyn \& Bacon/Pearson Education.

ten Klooster, P. M., Weekers, A. M., Eggelmeijer, F., van Woerkom, J. M., Drossaert, C. H. C. M., Taal, E., et al. (2010). Optimisme en/of pessimisme: Factorstructuur van de Nederlandse life orientation testrevised. Psychologie en Gezondheid, 38(2), 89-100. doi:10.1007/BF03089356.

van Woerkom, M., \& Meyers, M. C. (2014). My strengths count! Effects of a strengths-based psychological climate on positive affect and job performance. Human Resource Management,. doi:10.1002/hrm. 21623.

van Woerkom, M., \& Meyers, M. C. (2015). My strengths count! Effects of a strengths-based psychological climate on positive affect and job performance. Human Resource Management, 54(1), 81-103. doi:10. 1002/hrm.21623. 
Wang, L., Zhang, Z., McArdle, J. J., \& Salthouse, T. A. (2008). Investigating ceiling effects in longitudinal data analysis. Multivariate Behavioral Research, 43(3), 476-496.

Warr, P. (1999). Well-being and the workplace. In D. Kahneman, E. Diener, \& N. Schwarz (Eds.), Wellbeing: The foundations of hedonic psychology (pp. 392-412). New York: Russell Sage Foundation.

Watson, D., Clark, L. A., \& Tellegen, A. (1988). Development and validation of brief measures of positive and negative affect: The PANAS scales. Journal of Personality and Social Psychology, 54(6), 1063-1070.

Wood, A. M., Linley, P. A., Maltby, J., Kashdan, T. B., \& Hurling, R. (2011). Using personal and psychological strengths leads to increases in well-being over time: A longitudinal study and the development of the strengths use questionnaire. Personality and Individual Differences, 50(1), 15-19.

Zelenski, J., Murphy, S., \& Jenkins, D. (2008). The happy-productive worker thesis revisited. Journal of Happiness Studies, 9(4), 521-537.

Zwart, R. C., Korthagen, F. A. J., \& Attema-Noordewier, S. (2015). A strength-based approach to teacher professional development. Professional Development in Education, 41(3), 579-596. doi:10.1080/ 19415257.2014.919341. 